\title{
単原子層グラファイトで修飾された $\mathrm{Pt}(111)$ 表面における $\mathrm{C}_{2} \mathrm{H}_{6}$ 分子の非弾性散乱ダイナミクス
}

森 大輔*1 岡田 隆太*1 $\cdot$ 山本 恵彦*1

（受理2003年10月 28 日，掲載決定2004年 7 月 3 日）

\author{
Inelastic Collision Dynamics of a $\mathrm{C}_{2} \mathrm{H}_{6}$ Supersonic Molecular Beam \\ on a $\mathrm{Pt}$ (111) Surface Covered with a Graphite Monolayer \\ Daisuke MORI, Ryuta OKADA and Shigehiko YAMAMOTO \\ Institute of Applied Physics, The University of Tsukuba \\ 1-1-1 Tennoudai, Tsukuba, Ibaraki 305-8573, JAPAN
}

(Received October 28, 2003, Accepted July 3, 2004)

\begin{abstract}
Inelastic collision processes on a chemically inert mono-layer graphitie ( $\mathrm{MG}$ ) grown on a $\mathrm{Pt}(111)$ surface have been studied using a supersonic $\mathrm{C}_{2} \mathrm{H}_{6}$ molecular beam. In contrast to rare gases with similar masses, such as $\mathrm{Ne}$ or $\mathrm{Ar}$, it is found that the internal modes of $\mathrm{C}_{2} \mathrm{H}_{6}$ molecules play an important role in the energy transfer upon collision with the MG surface.
\end{abstract}

\section{1. 緒言}

解離反応の閾值を越える運動エネルギーを持った分子 を固体表面に照射し, 照射位置にて直接解離反応を実現 する反応系において，反応解析や制御を著しく困難にし ているのが固体表面における非弾性散乱によるエネル ギー散逸である.

多原子分子の場合, 表面との衝突による固体表面での フォノン励起のみならず, 分子の回転や振動励起によっ て運動エネルギーが散逸される. 特に超音速分子線を用 いる場合には, 断熱膨張時に一旦凍結された回転モード や一部の振動モードが固体表面との衝突により再び励起 されるために内部エネルギ一の影響は無視できない.

我々は過去に分子線散乱法を用いて Pt (111) 表面にお ける $\mathrm{CH}_{4}$ と $\mathrm{C}_{2} \mathrm{H}_{6}$ の直接解離吸着に関する反応速度の 表面温度依存性をフォノン励起の観点から議論した ${ }^{1)}$. 一方, 内部エネルギーについてはフォノン励起との明確 な分離ができないため詳細な検討を行うことができなか

\footnotetext{
*1 筑波大学物理工学系（テ305-8573 つくば市天王台 1-1-1）
}

った. なた，この系に沏いては反応の進行と共に, Pt (111) 表面に炭化水素ラジカルやグラファイトが形成さ れ清浄表面が維持できないため, フォノン励起に関して も厳密な解析が不可能であった.

$\mathrm{C}_{2} \mathrm{H}_{6}$ は $\mathrm{CH}_{4}$ に比較して, 多くの内部エネルギー自由 度を持っている. 本研究では, 単原子層グラファイトで 修飾された $\mathrm{Pt}(111)$ 表面を用い, 解離反応が進行しない 条件下での $\mathrm{C}_{2} \mathrm{H}_{6}$ 分子の非弾性散乱によるエネルギー散 逸過程, 即ち非弾性散乱ダイナミクスの解明を研究目的 とした.

なお, 本研究では $\mathrm{C}_{2} \mathrm{H}_{6}$ (分子量30) に比べて分子量 がやや小さい $\mathrm{Ne}$ (分子量20）とやや大きい Ar（分子量 40), 即ち内部エネルギ一構造を持たない同程度の分子 量を有する分子についても同様な実験を行い, $\mathrm{C}_{2} \mathrm{H}_{6}$ 分 子固有の非弾性散乱過程, 即ち並進エネルギーから回転 などの内部エネルギーへのエネルギ一変換過程を明らか にすることを目的とする.

\section{2. 実験方法}

本研究で用いた分子線散乱装置の概略図をFig. 1 に 


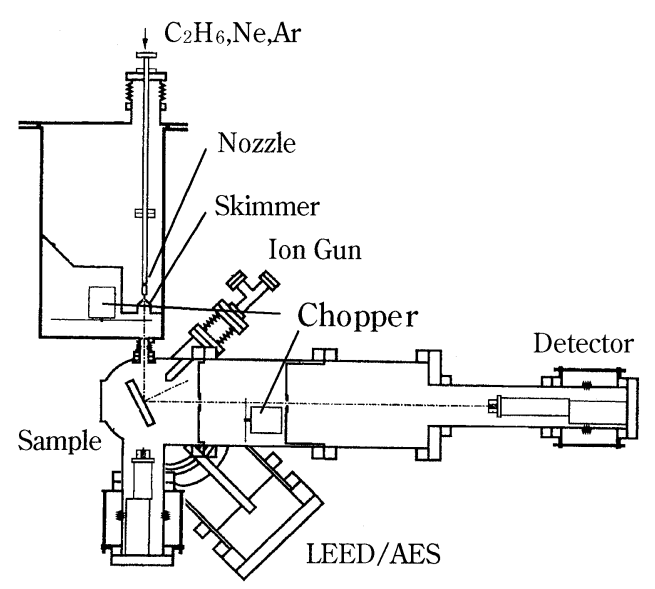

Fig. 1 Schematics of the molecular beam scattering apparatus.

示す，各室はそれぞれ独立に排気されており，base pressure は, $3 \times 10^{-8} \mathrm{~Pa}$ 以下の超高真空に保たれてい る. 線源室内のノズルから断熱膨張にて形成された分子 線は, スキマによって中心部分の流れの及在漉しとるこ とにより空間的指向性を高められ, 散乱室内の試料に照 射される. 試料から散乱された分子は検出室内に設置さ れた四重極質量分析計で検出される. 入射角度と散乱角 度の和は $90^{\circ}$ に固定されている. 試料表面に扮ける分子 線のビームスポット径は約 $3 \mathrm{~mm}$ である ${ }^{2)}$.

分子線のノズル温度は $300 \sim 900 \mathrm{~K}$ まで変化させた. 入射ガスとして $100 \%$ の $\mathrm{Ne}, \mathrm{Ar}$ 及び $\mathrm{C}_{2} \mathrm{H}_{6}$ とそれらを $\mathrm{He}$ 希釈した混合ガス $\left(\mathrm{Ne}: \mathrm{He}=1: 9, \mathrm{C}_{2} \mathrm{H}_{6}: \mathrm{He}=5\right.$ : 5, $\mathrm{Ar}: \mathrm{He}=4: 6)$ を分子線源として用いた. ノズル背 圧は $3 \mathrm{~atm}$ 一定とした. $\mathrm{Ne}, \mathrm{Ar}$ 及び $\mathrm{C}_{2} \mathrm{H}_{6}$ 分子線の並進 エネルギーはそれぞれ 166 から $327 \mathrm{meV}$ の間で変化させ た.なお，これらの分子線の並進エネルギーは単一スリ ットチョッパーを用いた飛行時間計測によって実験的に 計測されたものである.

$\operatorname{Pt}(111)$ 単結晶表面（純度 $99.99 \%$, 面方位精度 $0.4^{\circ}$ ) を, Arイオンスパッタリングと $750 \mathrm{~K}$ のアニーリング を繰り返すことにことにより清浄化した。

単原子層グラファイト (MG) 表面を作成するために, 清浄な $\mathrm{Pt}$ (111) 表面に $\mathrm{CH}_{4}$ 分子線を表面垂直方向より 照射した。照射条件は表面温度 $850 \mathrm{~K}$ ，入射エネルギー $750 \mathrm{meV}$, 照射時間は約 5 時間とした.なおこの条件に おいて $\mathrm{CH}_{4}$ を $\mathrm{Pt}$ (111)表面に照射すると $\mathrm{Pt}(111)$ 表面に 単原子層グラファイトが一面に形成されることが STM 観察によりすでに確認されている3). 照射後, LEED 測 定にて Pt(111) 表面上に MG 表面が作成されていること

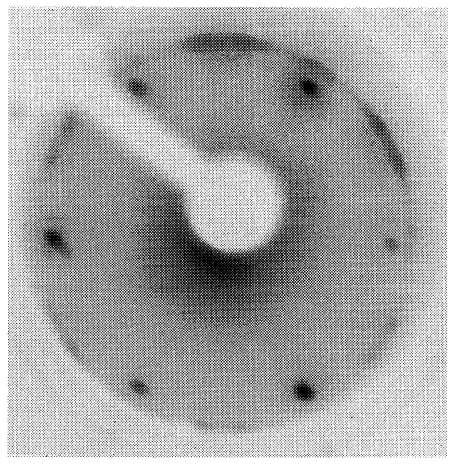

Fig. 2 LEED images of $\mathrm{Pt}(111)$ after irradiation of methane with $E_{\perp}=750 \mathrm{meV}$ at $850 \mathrm{~K}$.

を確認した。

単原子層グラファイト表面で修飾された $\mathrm{Pt}$ (111)表面 （以下 $\mathrm{MG}$ 表面々略す）からの $\mathrm{Ne}, \mathrm{Ar}$ 及び $\mathrm{C}_{2} \mathrm{H}_{6}$ 分子 の散乱強度角度分布計測を行った. 散乱強度角度分布計 測はサンプルを回転精度 $\pm 0.1^{\circ}$ で回転させて行った.こ の際 $\mathrm{CH}_{4}$ 分子線照射部, 即ち $\mathrm{MG}$ 形成部以外からの散 乱の寄与は小さく無視できるものとした．COの吸着が 無視できる表面温度 $500 \mathrm{~K}$ で一連の実験を行った。一つ の角度分布計測時間は約 30 分程度である。

\section{3. 実験結果}

入射エネルギー $750 \mathrm{meV}$, 表面温度 $850 \mathrm{~K}$ に $\mathrm{CH}_{4}$ を 5 時間照射した後の表面の LEED 像を Fig. 2 に示す. $\operatorname{Pt}(111)$ の周期性を示す六角形の回折スポット $(1 \times 1)$ の外側にリング状の回折スポットがあることがわかる. このリングの半径から表面にグラファイトが析出してい ることがわかる.

$\mathrm{MG}$ 表面からの $\mathrm{Ne}, \mathrm{Ar}$ 及び $\mathrm{C}_{2} \mathrm{H}_{6}$ 分子の散乱強度角 度分布をFig. 3 に示す．入射分子が一旦表面に捕獲さ れたことを示すコサイン分布が観測されていないことか ら，得られた分布がすべて直接非弾性散乱によるもので あることがわかる（この条件下での捕獲の可能性は少な い). 得られた分布に执いて半值幅とピーク位置につい てまとめた結果を Fig. 4 に示す. それぞれ，丸が Ar, 三角が $\mathrm{Ne}$, 四角が $\mathrm{C}_{2} \mathrm{H}_{6}$ のピーク位置及び半值幅を示 している. Neに比べ Arのピーク位置及び半值幅の值 が大きい．このことは表面原子と入射分子の古典的な 2 体の剛体衝突モデルを考えることで定性的に理解でき る ${ }^{4)} \cdot \mathrm{C}_{2} \mathrm{H}_{6}$ のピーク位置は $\mathrm{Ar}$ と同じ領域にあり, 半值 幅は $\mathrm{Ne}$ 及び $\mathrm{Ar}$ よりも大きい. $\mathrm{C}_{2} \mathrm{H}_{6}$ 分子量が $\mathrm{Ne}$ と $\mathrm{Ar}$ の間の值を持つことから, $\mathrm{C}_{2} \mathrm{H}_{6}$ のピーク位置及び半値 幅とも $\mathrm{Ar}$ と Ne の間の領域にあると予想される。しか 

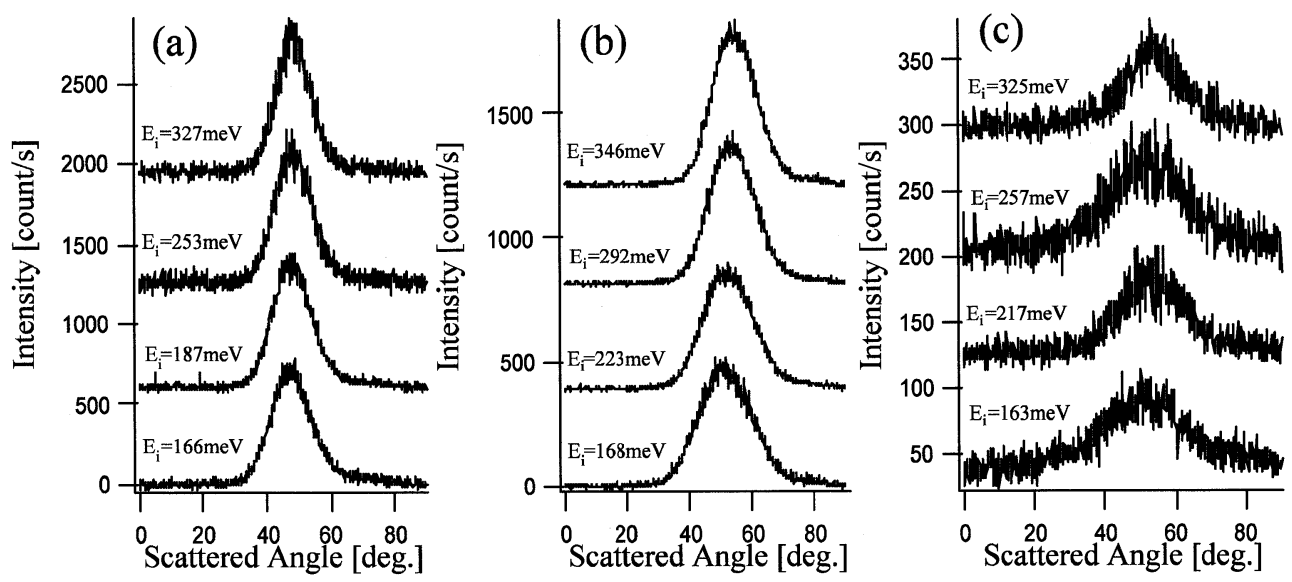

Fig. 3 Angular intensity distribution of neon (a), argon (b), and ethane (c) molecules scattered from MG/Pt(111).
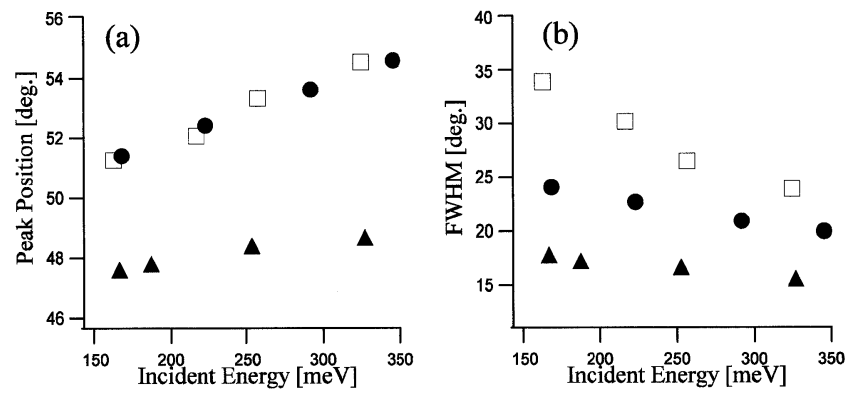

Fig. 4 Peak positions (a) and FWHMs (b) of the angular intensity distribution of neon (triangles), argon (circles), and ethane (open squares) molecules scattered from a MG/Pt(111) surface as a function of the incident energy.

し, $\mathrm{C}_{2} \mathrm{H}_{6}$ は予想される領域から逸脱しており, 特に半 值幅でその度合いが大きいことが Fig. 4 よりわかる.

これは $\mathrm{C}_{2} \mathrm{H}_{6}$ の分子構造及び内部自由度に起因するもの と考えられる。

\section{4. 考察}

$\mathrm{C}_{2} \mathrm{H}_{6}$ 分子は直線分子構造を持つダンベル型の分子で ある. $\mathrm{C}_{2} \mathrm{H}_{6}$ 分子が $\mathrm{MG}$ 表面と衝突する際に, 分子自身 の内部モードの励起が起こると考えられる. Fig. 4 にお いて, $\mathrm{C}_{2} \mathrm{H}_{6}$ のピーク位置が希ガスの測定結果より予想 される領域よりも高散乱角側にあるのは, $\mathrm{C}_{2} \mathrm{H}_{6}$ 表面衝 突時における $\mathrm{C}_{2} \mathrm{H}_{6}$ 分子の回転モード励起により並進工 ネルギーが回転エネルギーへ散逸し, 表面垂直方向のモ メンタムが減少したためである.

$\mathrm{MG}$ 表面は $\mathrm{C}_{2} \mathrm{H}_{6}$ 分子にとって平坦であり, 衝突の前 後で表面接線方向のモメンタムがほぼ保存されていると 仮定すれば，並進エネルギーが回転エネルギーへと変換 されることで, $\mathrm{C}_{2} \mathrm{H}_{6}$ のピーク位置が予測に比べ高散乱
角側にあることが理解される.

$\mathrm{C}_{2} \mathrm{H}_{6}$ の測定結果 (半值幅) が希ガスの測定結果より も大きい值を示すのは回転励起によりさまざまな散乱分 子の成分が重畳するためである.

$\mathrm{C}_{2} \mathrm{H}_{6}$ 分子の回転モードには散乱分子の真空空間にお ける回転モード励起と表面での回転運動励起が考えられ る. 表面での回転運動励起としては Cartwheel 回転と Helicopter 回転に分類される. Cartwheel 回転モードは 平坦な表面でも励起されやすいが，Helicopter 回転モー ドは平坦な表面では励起されにくい5)，MG 表面は $\mathrm{C}_{2}$ $\mathrm{H}_{6}$ 分子にとって平坦であると考えられ，本実験では主 にCartwheel 回転が励起されていると考えられる.

$\mathrm{C}_{2} \mathrm{H}_{6}$ の並進エネルギーが一旦, Cartwheel 回転エネ ルギーへと蓄えられ, 数回の表面原子と衝突後, 再び並 進エネルギーと変換され, 表面より散乱していく散乱過 程(チャタリング衝突過程)が起きていると考えられる.

この結果, さまざまな散乱分子の成分が重畳し半値幅が 広がることが考えられる。 

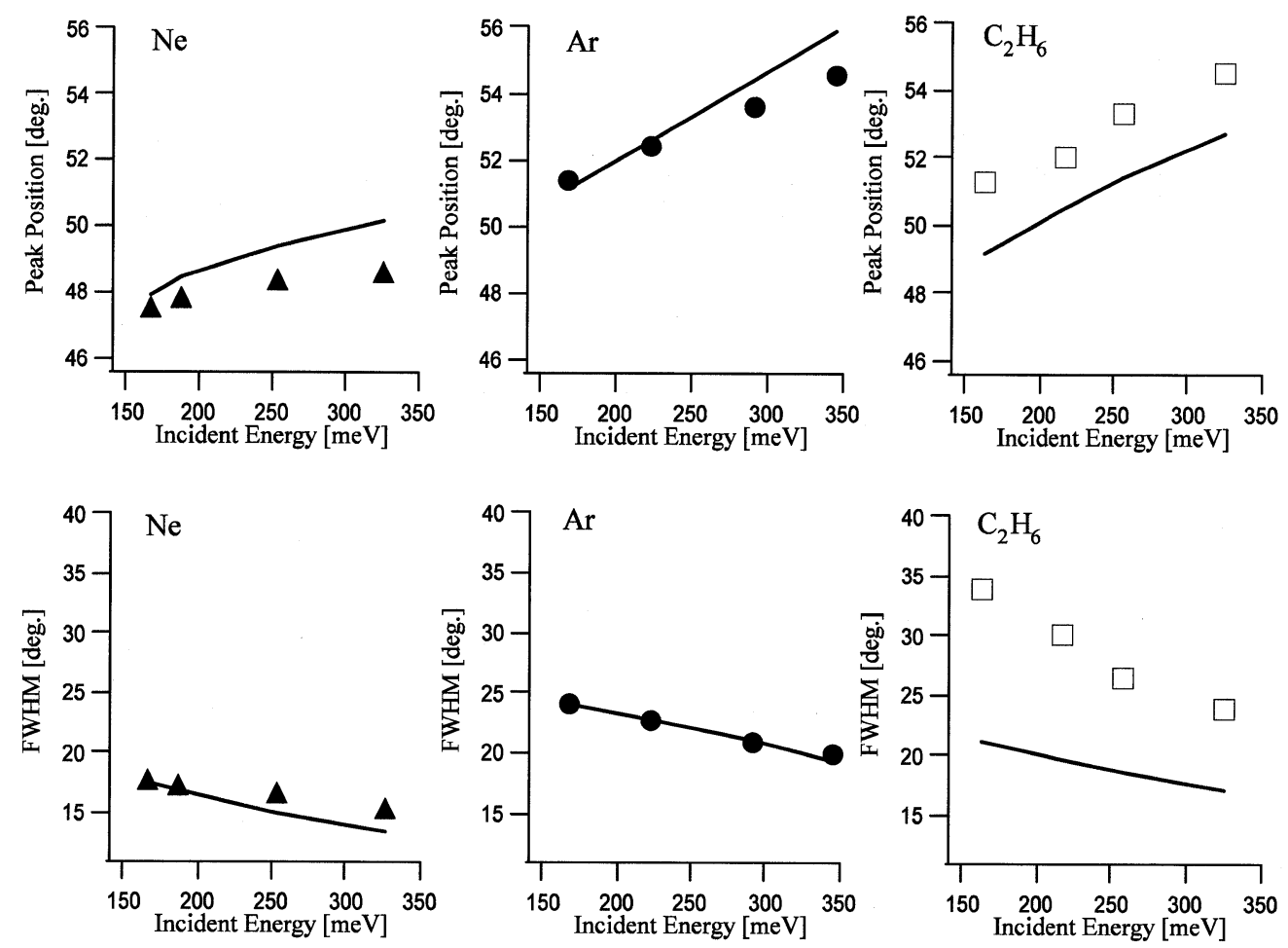

Fig. 5 Peak positions and FWHMs of the angular distribution of neon, argon, and ethane molecules from a surface compared with the prediction of the Hard Cube model for monoenergetic incident beam and the surface masses 72 . Experimental data are indicated by markers, while the HCM calculations are indicated by solid lines.

また表面との衝突により高エネルギーの振動モードが 励起されれば，表面垂直方向のモメンタムが減少するこ とになるが，この条件に抢ける振動モードの励起確率は 非常に低いと報告されている5 .

\section{Hard Cube Model との比較}

得られた結果を定性的に解釈するため古典的な 2 体衝 突モデルである Hard Cube Model ${ }^{4)}$ (以下 HCM と略す) との比較を行った.このモデルは, 重い表面元素におけ る軽い入射分子の非弾性散乱を定性的に説明するもので ある．また，Grimmelmann吕らは，HCM で考える表面 の質量は，表面原子の質量よりは重いと報告している. そこで表面の質量を72 amu（C6 個の質量に対応）とし た時の $\mathrm{HCM}$ で予測される $\mathrm{Ne}, \mathrm{Ar}$ 及び $\mathrm{C}_{2} \mathrm{H}_{6}$ のピーク 位置及び半值幅を測定結果と比較した。その結果を Fig. 5 に示す．Ne及びArにおいては，測定結果と計 算値がよく一致していることがわかる。一方， $\mathrm{C}_{2} \mathrm{H}_{6}$ に おいてはピーク位置については, 測定結果が計算值より も高散乱角側にあり，半値幅については計算値を大きく 逸脱していることがわかる．HCMに抢いては質点系の 衝突を仮定して抢り，分子の内部自由度は考慮されてい
ない．このため $\mathrm{C}_{2} \mathrm{H}_{6}$ の測定結果は計算值を逸脱すると 考えられ，その傾向は半値幅について顕著であることが わかる。

\section{5. 結 言}

本研究では単原子層グラファイトで修飾された $\mathrm{Pt}$ (111) 表面に扮ける $\mathrm{C}_{2} \mathrm{H}_{6}$ 分子の非弾性散乱ダイナミク スを解析するために，分子量の近い $\mathrm{Ne}$ （分子量20）及 び $\mathrm{Ar}$ （分子量40）分子と比較して $\mathrm{C}_{2} \mathrm{H}_{6}$ 分子（分子量 30）の散乱強度角度分布計測を様々な入射エネルギーに おいて行った，その結果，次のことが明らかになった。

(1) $\mathrm{Ne}, \mathrm{Ar}, \mathrm{C}_{2} \mathrm{H}_{6}$ の全てに対して，入射エネルギー の增加と共に得られた角度分布のピーク角度は増加し， 半値幅は減少する.

(2) Hard Cube Modelにより Ne及び Arの角度分布 スペクトルは説明できるが， $\mathrm{C}_{2} \mathrm{H}_{6}$ の場合は説明できな い. 表面と衝突する際, その並進エネルギーを内部エネ ルギー（主に回転エネルギー）へ変換する事により Hard Cube Model では説明できない特徵的な散乱現象 が $\mathrm{C}_{2} \mathrm{H}_{6}$ 分子では起こっているものと判断される. 


\section{〔文献〕}

1) S. Yagyu, T. Hiraoka, Y. Kino and S. Yamamoto: Appl. Surf. Sci., 165 (2000) 217.

2) F. Murakami, S. Yagyu, E. S. Gillman, M. Mizunura, Y. Takeishi, Y. Kino, H. Kita and S. Yamamoto: J. Surf. Anal., 3 (1997) 481.

3）植田寛和, 才田守彦, 中井 力, 山田洋一, 佐々木
正洋, 山本恵彦 : 真空, (投稿中)

4) R. M. Logan and R. E. Stickney: J. Chem. Phys., 44 (1966) 195.

5) J. A. Stinnett, R. J. Madix and J. C. Tully: J. Chem. Phys., 104 (1996) 3134.

6) E. K. Grimmelmann, J. C. Tully and M. J. Cardillo: J. Chem. Phys., 72 (1980) 1039. 